\title{
Novel Eco-friendly Additives for Aqueous and Non-aqueous Fluid Design
}

\author{
Md Amanullah and Jothibasu Ramasamy \\ Drilling Technology Team, EXPEC ARC, Saudi Aramco, Dhahran 31311, Saudi Arabia
}

\begin{abstract}
The global oil and gas industry has a long standing initiative to develop and use the most environment friendly solutions in the exploration and exploitation of oil and gas resources to prevent any damage or degradation of other marine and terrestrial resources. This is reflected by increasing research in academics, research institutes and organizations around the globe to develop better and more environment friendly base fluids, viscosifiers, fluid loss additives, emulsifiers, lubricants, etc. to protect the local, regional and global environments, eco-systems, habitats and also the OHS of workers and professionals working in the oil and gas industry. This paper describes the development, testing and evaluation of several novel additives to demonstrate their suitability for oil and gas field applications to avoid any negative impact to the surrounding environment. Experimental results indicate that the newly developed additives provide desirable, similar or better performance with respect to conventional additives used by the industry and thus demonstrate their suitability for application in aqueous and non-aqueous fluid design. The plant-based organic additive identified to use as an ecofriendly viscosifier for aqueous mud system can also control the fluid loss behavior of clay free system and thus can act as a bi-functional additive. Several waste vegetable oil-based eco-friendly additives have been developed for their application as spotting fluids, base oil and emulsifiers for invert emulsion oil based mud. These additives have similar or better technical performance than the equivalents and the eco-friendly nature of the mud additives demonstrates their ability to perform the functional tasks with better protection of the surrounding environments.
\end{abstract}

Key words: Eco-friendly additives, waste vegetable oil based additives, drilling fluids, emulsifiers, spotting fluids, base oil, viscosifiers.

\section{Introduction}

Analyses of the challenges encountered while drilling indicate the importance of environmental challenges as one of the key issues in addition to the technical and logistic challenges encountered for safe and economic drilling operation. Hence, it is very important to address the environmental issues associated with the non-ecofriendly additives and chemicals to encourage the industry, research organizations, academics, etc. to shift from the less ecofriendly additives to more eco-friendly chemicals and additives by conducting research and development for producing eco-friendly alternatives to non-ecofriendly products and additives. The oil and gas industry has taken the environmental issues associated with traditional additives and

Corresponding author: Md Amanullah, Ph.D., Sr. pet. eng., consultant, petroleum eng., research field: drilling fluids. chemicals very seriously. This is reflected in their keen interest to introduce more and more green additives for various fluids designed for exploration of oil and gas resources without damaging other terrestrial and marine resources. Collaborations and active participation of the oil and gas industry with academics, institutes and research organizations to develop virtually non-toxic, readily biodegradable and environmentally benign green chemicals and additives clearly demonstrate their commitment to safeguard the global environment. Industry funded past and present research conducted by various organizations also highlighting the need of development of green chemicals and additives for designing high performance drilling and completion fluids, loss control slurry, fracturing and stimulation fluids, etc. [1-4].

Worldwide highlights on the benefits and advantages of ecofriendly fluid additives over the non-ecofriendly 
chemicals and additives have accelerated the research activities around the globe to safeguard the environments, ecosystems, habitats, sensitive marine and terrestrial environments, etc. This is reflected in the increasing research in academics, research organizations, service companies to develop ecofriendly base fluids, readily biodegradable chemicals and polymers, virtually non-toxic additives and fluid components to replace or reduce the use of less eco-friendly additives and chemicals [5-14]. This is manifested by the progressive replacement of diesel by mineral oil, mineral oil by highly refined mineral oil and highly refined mineral oils by synthetic-based oils and the desire to replace the synthetic-based oils by plant or vegetable oils.

Various authors [15-17] have highlighted the progressive shift of the industry towards the green additives and chemicals to exclude the use of diesel and mineral oil-based products as EPA and other regulatory bodies are now applying extremely high restrictions in using diesel and mineral oils and also their derivatives $[3,18,19]$.

The positive impact of these laws and regulations is reflected in the development of plan by various countries to cut the use of non-ecofriendly chemicals and additives and increase the use of ecofriendly alternatives of these products. This is reflected in the annual introduction of 7 to $10 \%$ eco-friendly lubricants in the U.S. market compared to an overall $2 \%$ growth of conventional lubricants $[5,6]$.

Adoption of strict operational guidelines when using non-ecofriendly fluids and additives may not provide a viable solution to protect the environment. Because in spite of strict operational guidelines and best drilling practices, sometimes accidental spills, leakage and discharge of fluids and additives may occur leading to the damage and degradation of the surrounding environment, water systems, farming land, top soil, coastal areas, etc. Hence, a better alternative is the replacement of the non-ecofriendly, poorly biodegradable and toxic additives and chemicals by eco-friendly, readily biodegradable and virtually non-toxic products. It is reflected in the introduction of mineral oil to replace the diesel oil and the introduction of synthetic oil-based fluids ( $\mathrm{SOBFs}$ ) to replace the mineral oil-based fluids. SOBFs are much less toxic than diesel and mineral oils and has higher degradation rate compared to these oils. However, it is neither virtually non-toxic nor readily biodegradable, especially in anaerobic condition of sea bottom. This again highlights the need of novel fluid additives that are readily biodegradable and highly environment friendly to eliminate any cumulative and long term effect of the low toxicity, low aromatic and low paraffin containing SOBFs.

Plant-based materials and organic oil are thought to have the best environmental characteristics compared to SOBFs. It is readily biodegradable both in aerobic and anaerobic conditions and therefore expected to disappear in sea bottom environment. The organic oil ester of plant or vegetable origin has the lowest volatile vapor content compared to SOBFs that has been used to replace the diesel and mineral oils. It has no aromatic and paraffin content to create any cumulative or long term impact on the surrounding environments. Hence, development of vegetable oil-based ester, lubricants, emulsifiers, etc. can provide a better alternative to SOBFs and their derivatives. This paper describes the testing and evaluation of several novel ecofriendly additives developed for aqueous and non-aqueous drilling fluid systems to be in the forefront of best drilling practices both in onshore and offshore drilling environments.

\section{Eco-Friendly Additives for Aqueous Drilling Fluid}

Fresh, sea and salt water-based aqueous drilling muds have been used for drilling fluid applications. These fluids are eco-friendly, virtually not-toxic and readily biodegradable if the ingredients used in the fluid design are selected to fulfill the environmental compliance set by EPA, local, regional and federal 
governments. However, due to some special drilling conditions and technical challenges, some additives that are added to the aqueous mud system can reduce the environmental standing of the aqueous drilling muds significantly. For example, addition of non-ecofriendly diesel and mineral oils and their derivatives such as diesel and mineral oil-based lubricants, emulsifiers, surfactants into an aqueous mud can reduce the environmental standing of water-based muds significantly and thus may cause serious degradation of sensitive environments and eco-systems including the mobility, mortality, fertility and reproductive capacity of the surrounding habitats.

Diesel and mineral oil-based spotting fluids are used to recover a stuck pipe created in the presence of a water-based mud. The use of this type of spotting fluid may cause a shift of the environmental standing of water-based mud due to serious contamination of the mud system by the left over spotting fluid. Hence, it is desirable to use an eco-friendly, virtually non-toxic and readily biodegradable spotting fluid to recover a stuck pipe to prevent any shift of the environmental standing of the original water-based muds. The below section describes several ecofriendly products that have been developed to protect the environmental characteristics of water-based muds for their applications in environment sensitive areas to prevent any damage and degradation to other marine and terrestrial resources.

\subsection{Eco-Friendly Bi-Functional Additive}

A plant-based eco-friendly bi-functional additive (BFA) was developed by physical processing of the outer shell i.e. the light weight husky portion of the psyllium seeds. After grinding the raw seed husks, sieve analysis was conducted to separate the less than 250 microns size particles and evaluate the bi-functional characteristics i.e. simultaneous action as fluid viscosifier and fluid loss additive. An unweighted bentonite mud containing $22.5 \mathrm{ppb}$ bentonite in $350 \mathrm{cc}$ fresh water was used to evaluate the viscosifing potential of the BFA. The base bentonite mud and the bentonite mud with same amount of XC polymer were also used to compare the results. In addition to the viscous profiles, 10 seconds and 10 minutes gel strength were also measured to evaluate the gelling characteristics of the BFA with respect to bentonite particles and also the combination of bentonite particles and XC polymer. Zero point five (0.5) gm XC and BFA were used to maintain the same concentration of the traditional XC and new BFA in the mud. The components of the mud were mixed properly using a high speed mixture to make a homogeneous drilling mud without the formation of any fish eyes or lumps. Standard viscosity measurement apparatus was used to determine the rheological profiles and gel strength characteristics both at ambient condition and after hot rolling at $100{ }^{\circ} \mathrm{C}$ for 16 hours.

\subsubsection{Viscous Characteristics Assessment}

Fig. 1 shows the viscous profile of the base bentonite mud and also the bentonite mud containing $0.5 \mathrm{gm} \mathrm{XC}$ polymer and $0.5 \mathrm{gm}$ BFA. The data clearly indicate the improvement of the viscous profile of the bentonite mud after the incorporation of the BFA and also XC polymer into the mud system. Hence, the BFA clearly demonstrates its functional capability as a viscosifying agent. Comparison of the viscosity enhancing capacity of the BFA with the traditional XC polymer indicates nearly similar viscosity generating potential in bentonite mud system. Fig. 2 shows the viscous characteristics after hot rolling the mud systems for 16 hours at $100{ }^{\circ} \mathrm{C}$. There is an improvement in viscous profiles of all the muds after thermal aging. These viscous profiles also indicate nearly similar viscosifying characteristics both for the BFA and the $\mathrm{XC}$ polymer. Therefore, the BFA is a new addition of ecofriendly viscosifier in the bank of eco-friendly additives.

\subsubsection{Gelling Characteristics Assessment}

Fig. 3 shows the 10 seconds and 10 minutes gel strength characteristics of the base bentonite mud and also bentonite mud containing $0.5 \mathrm{gm} \mathrm{XC}$ polymer and $0.5 \mathrm{gm}$ BFA. The data clearly indicate the improvement 


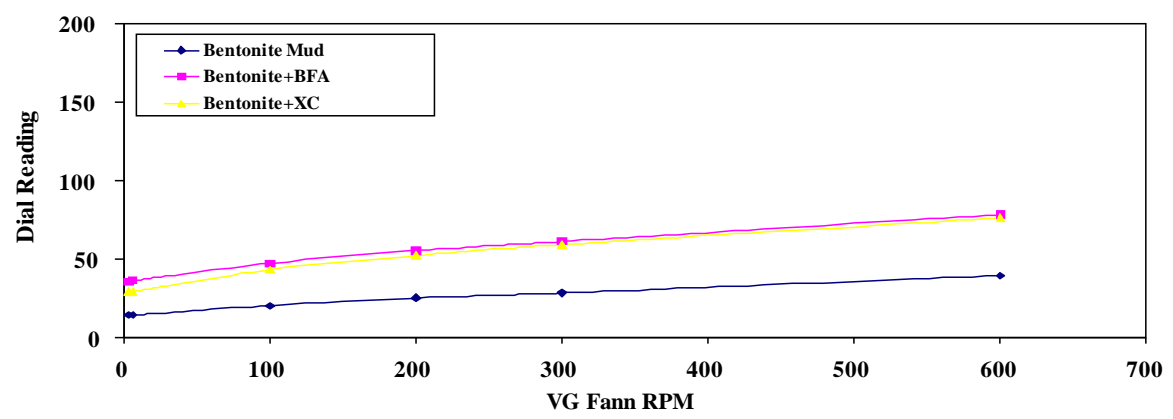

Fig. 1 Comparative evaluation of the rheological profile of the BFA and XC polymer at ambient condition.

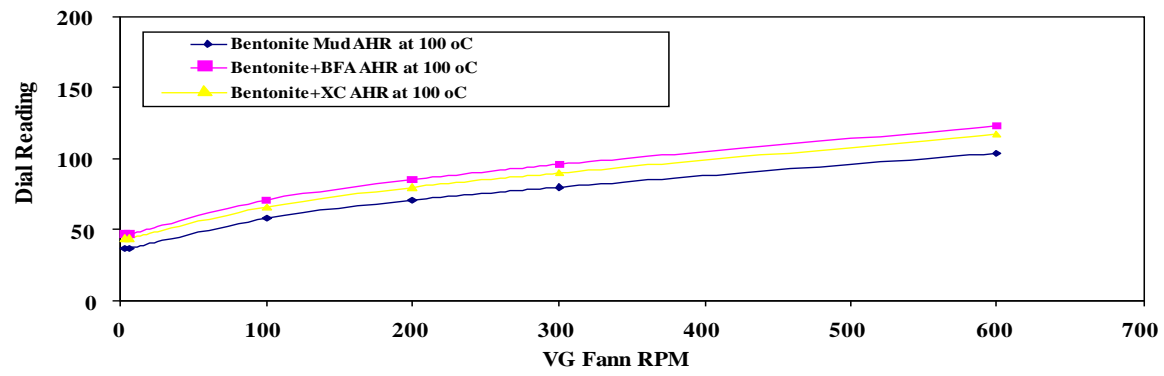

Fig. 2 Comparative evaluation of the rheological profile of the BFA and $\mathrm{XC}$ polymer after hot rolling at $100{ }^{\circ} \mathrm{C}$.

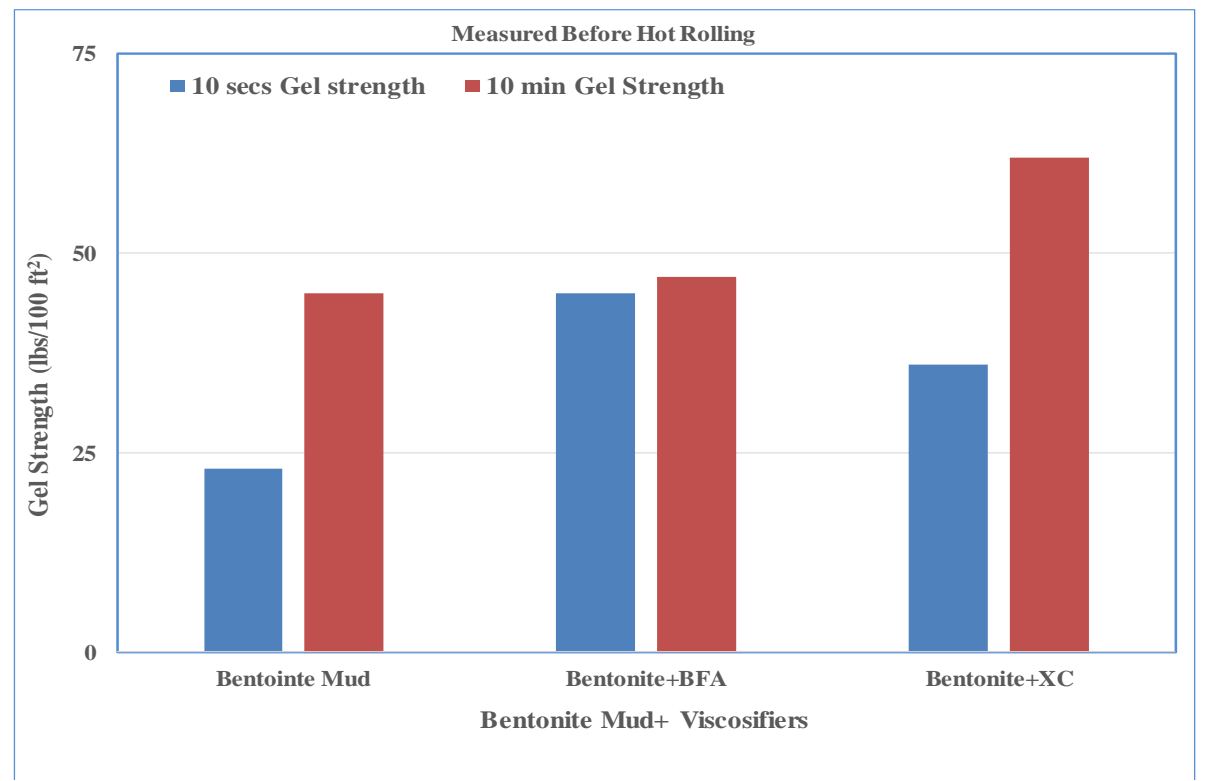

Fig. 3 Comparative evaluation of the gel strength values of BFA and XC polymer before hot rolling

of the gel strength behavior of bentonite mud after the incorporation of the $\mathrm{BFA}$ and $\mathrm{XC}$ polymer into the mud system. It clearly demonstrates the ability of the BFA to enhance the gelling behavior of bentonite mud, compared to the gel enhancing nature for $\mathrm{XC}$ polymer. BFA indicates better 10 seconds gel strength than the $\mathrm{XC}$ polymer and thus indicates its quicker ability of gelling after the cession of the mud circulation pump. However, the $\mathrm{XC}$ polymer shows higher 10 minutes gel strength compared to the 10-minute gel strength of BFA. The BFA also shows flat nature of the gel strength which is reflected by nearly equal 10 seconds and 10 minutes gel strength. This type of gel characteristic is highly desirable for easy starting of 
recirculation without creating any pressure spikes. The $\mathrm{XC}$ polymer containing mud, on the other hand, shows progressive gel characteristics i.e. the 10 minutes gel strength is much higher than the 10 seconds gel strength. Higher pump pressure is needed to restart the circulation in this case which may cause induced fracturing of weak formations. Fig. 4 shows the gel strength characteristics after hot rolling the mud system for 16 hours at $100{ }^{\circ} \mathrm{C}$. There is some improvement of the gelling characteristics of all the muds after thermal aging of the muds. Again, the BFA showed higher 10 seconds gel strength compared to the traditionally used XC polymer. Hence, the BFA is a new addition of ecofriendly viscosifier to enhance both the viscous and the gelling characteristics of bentonite muds, especially in preparing high viscous sweeps to improve the hole cleaning efficiency.

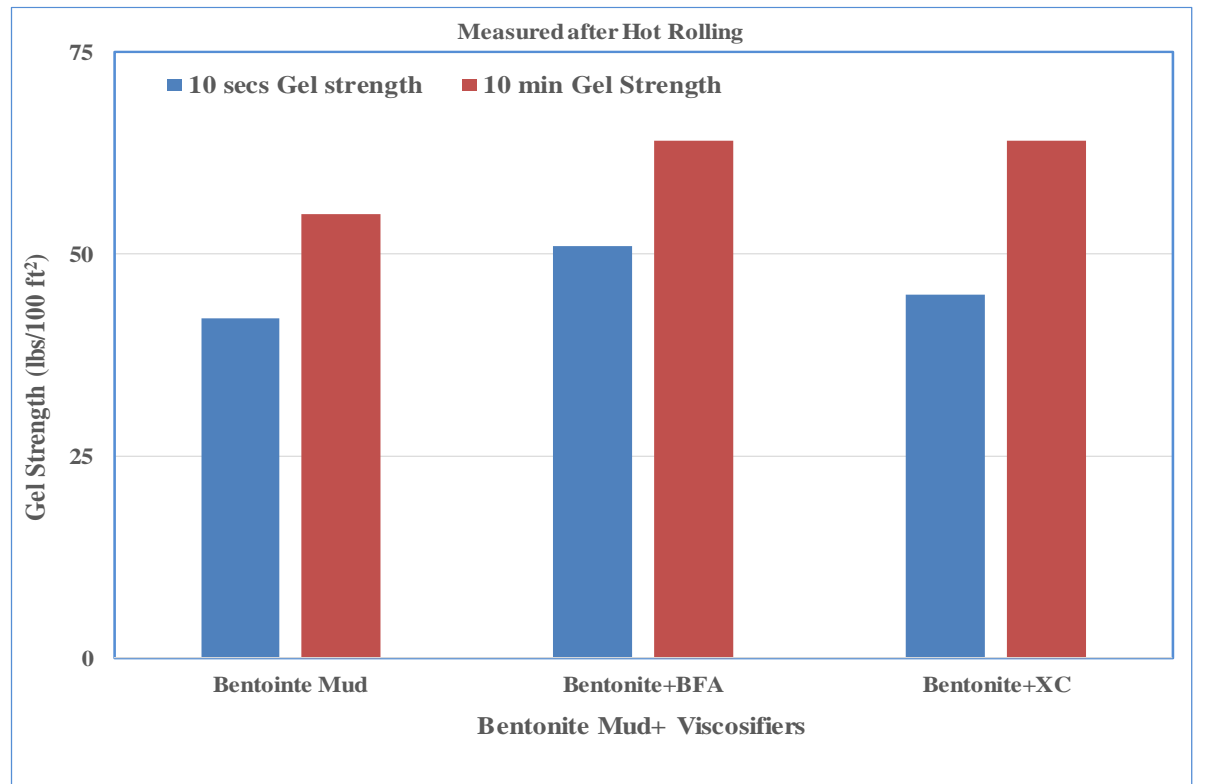

Fig. 4 Comparative evaluation of the gel strength values of the BFA and $\mathrm{XC}$ polymer after hot rolling at $100{ }^{\circ} \mathrm{C}$.

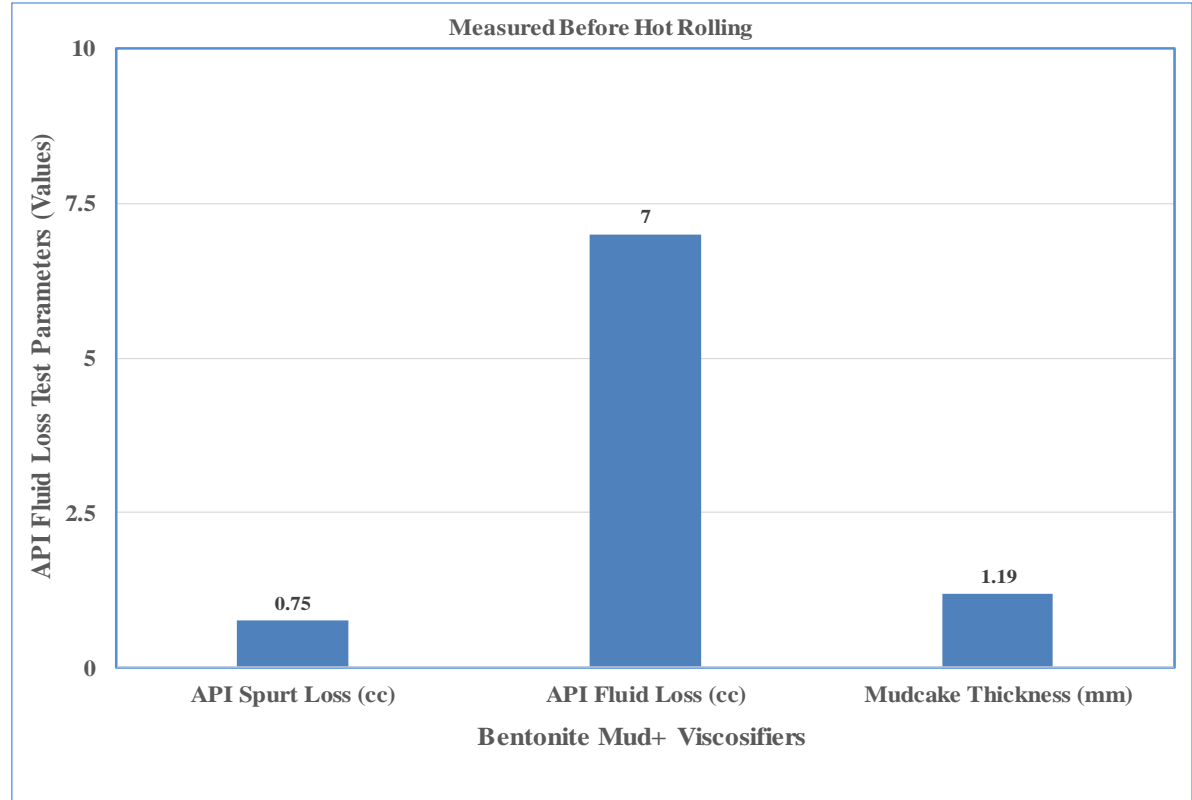

Fig. 5 API fluid loss behavior of BFA containing salt water-based mud before hot rolling. 


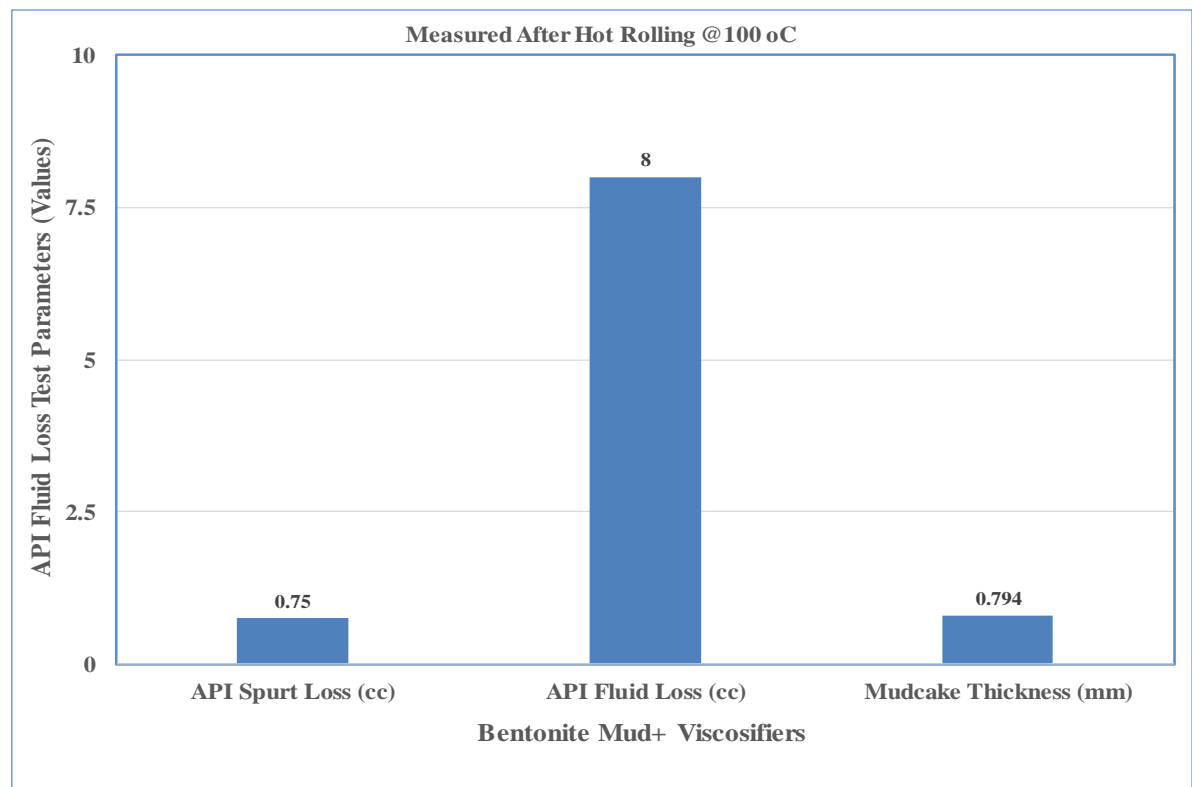

Fig. 6 API fluid loss behavior of BFA containing salt water-based mud after hot rolling at $100{ }^{\circ} \mathrm{C}$.

\subsubsection{Fluid Loss Characteristics Assessment}

A clay-free salt water-based mud containing 129.5 $\mathrm{gm} \mathrm{NaCl}$ and $290 \mathrm{cc}$ water was prepared. Then $3 \mathrm{gm}$ $\mathrm{XC}$ polymer and $2.5 \mathrm{gm}$ BFA were added and mixed with the salt water system using a high speed mixture. API filtration test was run using the mud both before and after hot rolling the salt water-based mud. Figs. 5 and 6 show experimental results.

Fig. 5 shows the API fluid loss characteristics of a clay free salt water-based mud at ambient temperature. The data clearly show very low spurt loss and also API fluid loss. The data further show the deposition of a very thin mudcake. All these parameters demonstrate the high potential of the BFA to use as a fluid loss additive for salt water-based muds. Fig. 6 shows the API fluid loss characteristics after hot rolling the salt water-based mud at $100{ }^{\circ} \mathrm{C}$ for 16 hours. The data again show excellent fluid loss control capability of the BFA even after the thermal aging of the mud at $100{ }^{\circ} \mathrm{C}$ temperature for 16 hours. The results clearly show some improvement of the mudcake characteristics after thermal aging of the mud. These data again demonstrate that the BFA is not only an addition to the bank of ecofriendly viscosifier but also to the bank of eco-friendly fluid loss control additives.

\section{Eco-Friendly Additives for Non-aqueous Drilling Fluid}

Due to poor technical performance of aqueous drilling muds in drilling reactive shales, marls, halites and evaporates and also their poor thermal, chemical, physical and long term stability in extreme drilling environments such as in HTHP and acid gas environments, the industry frequently uses diesel and mineral oil-based non-aqueous fluids to overcome the technical challenges associated with these troublesome formations and extreme drilling environments. Most of the additives used in the design of diesel and mineral oil-based mud formulation such as the emulsifiers, surfactants, base fluids, etc. are also non-eco-friendly as they are usually derivatives of diesel and/or mineral oils. In spite of negligence in the early stage of drilling, the industry realized the environmental impact of these non-aqueous fluids and additives after using them for a while in various parts of the globe. Their damaging impact was highly critical for sensitive environments, especially in some part of the globe. That is why the environmental regulatory bodies of various countries were enacting increasingly strict environmental laws and regulations to restrict or prevent the use of diesel and mineral oil-based base fluids. As the industry 
realized the short and long term impact of these non-aqueous fluids after the practical observation of their detrimental impact in some part of the globe, the industry started to identify and develop eco-friendlier, more biodegradable and less toxic non-aqueous fluids and additives to safeguard the global environment. This led to the development of less damaging and low toxic synthetic oil-based fluids.

Even though the synthetic oil-based fluids (SOBFs) and their derivatives are far better than the diesel and mineral oil-based muds and their derivatives, there are some restrictions to use these fluids in some part of the world. This is due to the possibility of chronic and long term detrimental impact of synthetic oil-based mud cuttings on the disposal sites, the surrounding environments, habitats and benthic communities, etc if accumulated for a long time. Various authors and researchers [20-22] highlighted the impact of SOBFs and synthetic oil-based mud cuttings on the surrounding habitats and burial environments. Moreover, the synthetic oil-based fluids are not completely biodegradable under anaerobic conditions of the sea bottom. Hence, some countries of the world have high restrictions on the use of SOBFs and disposal of SOBF cuttings. Neff et al. [23] published a report based on several field studies to demonstrate the environmental aspect of the use of SOBFs. In these studies, the biological effects of discarded SOBF cuttings were monitored for a long period of time to evaluate the time dependent effect on the environment and the surrounding habitats. The authors demonstrated that the accumulated base fluid has high concentrations in sediments and has adverse effects in benthic communities of the disposal site. This again highlights the need of novel fluid additives that are readily biodegradable, highly environment friendly and virtually nontoxic.

\subsection{Eco-Friendly Base Fluid}

To overcome the restrictions and limitations of the conventional OBM systems, vegetable oil which is virtually non-toxic, readily biodegradable and highly eco-friendly can be used to develop eco-friendly base fluid to design and develop Eco-OBM to protect the global environment. However, due to a negative impact on consumer market for its use as a raw material for oil and gas industry application, it was excluded as a viable candidate. Waste vegetable oils generated by the food and catering industry have the same positive attributes as the original vegetable oil and thus an attractive candidate for eco-friendly base fluid development. Hence, a virtually non-toxic, readily biodegradable and highly ecofriendly base fluid was developed by physical and chemical processing and treatment of a blend of waste vegetable oils.

Fig. 7 shows the viscous characteristics of the refined waste vegetable oil (RWVO) along with the viscous characteristics of original waste vegetable oil, mineral oil and a highly refined Saudi Arabian mineral oil (SAO). The data clearly show extremely high viscous characteristics for the original waste vegetable oil. Due to the high viscosity of the waste vegetable oil, the waste vegetable oil as received is not suitable for development of a functional Eco-OBM. Hence, it is not a suitable candidate for Eco-OBM development. The refined waste vegetable oil (RWVO) shows drastic reduction in the viscous profile compared to the original waste vegetable oil. Comparison of the viscous profile of the refined waste vegetable oil with respect to the viscous profiles of the mineral and the Saudi Arabian oil indicates very similar characteristics. Hence, the refined waste vegetable oil can be used as a potential candidate for Eco-OBM development.

Fig. 8 shows the yield point (YP) and the plastic viscosity (PV) of a Saudi Arabian Oil-based mud (SAO Mud) and the newly developed waste vegetable oil ester based mud (WVO mud). The data clearly show much higher PV and YP values for the waste vegetable oil-based mud. These properties can be optimized by using lower amount of organophilic clays while designing the OBM system. The preliminary test results clearly demonstrate the high potential of using 


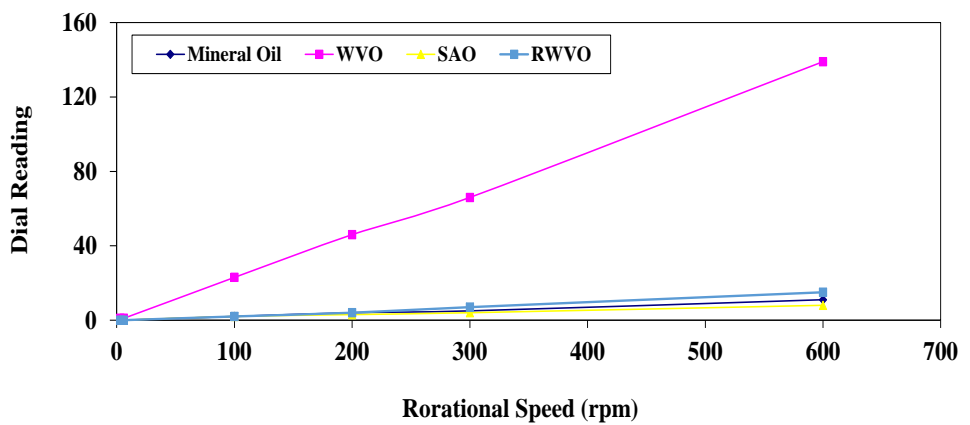

Fig. 7 Graphs showing rheological profiles of mineral oil, WVO, SAO and RWVO.

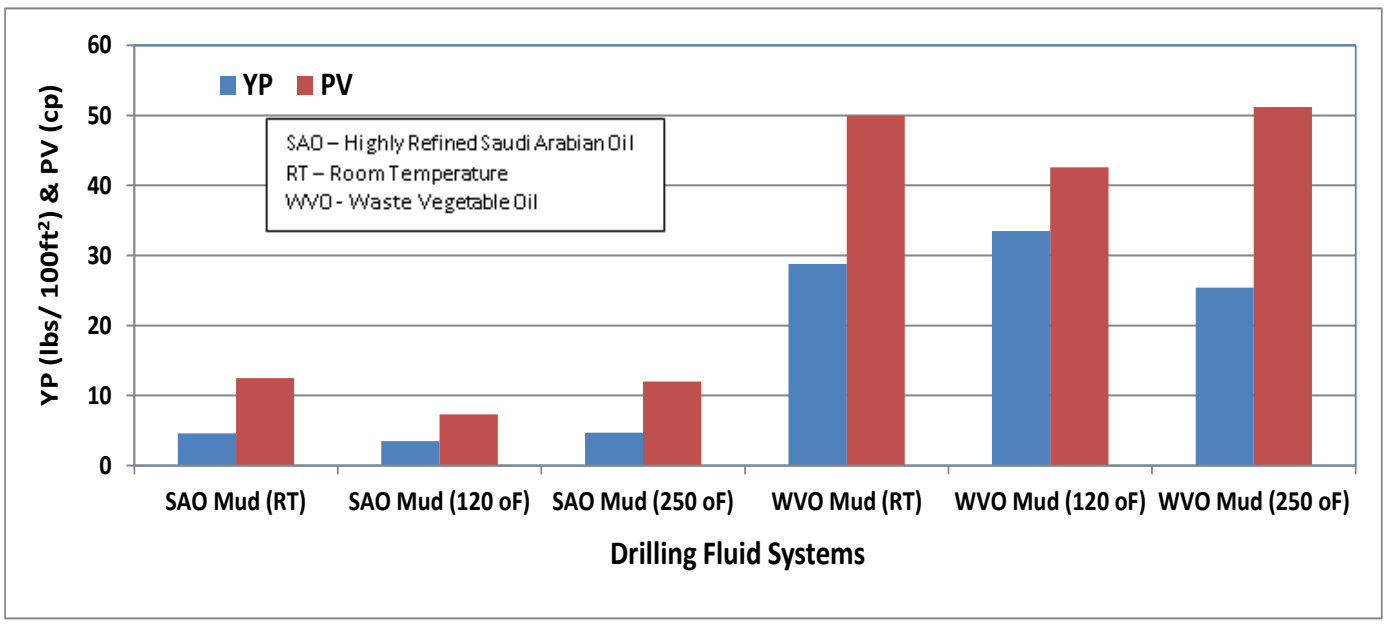

Fig. 8 Comparison of the PV and YP values of SAO and WVO-based drilling muds.

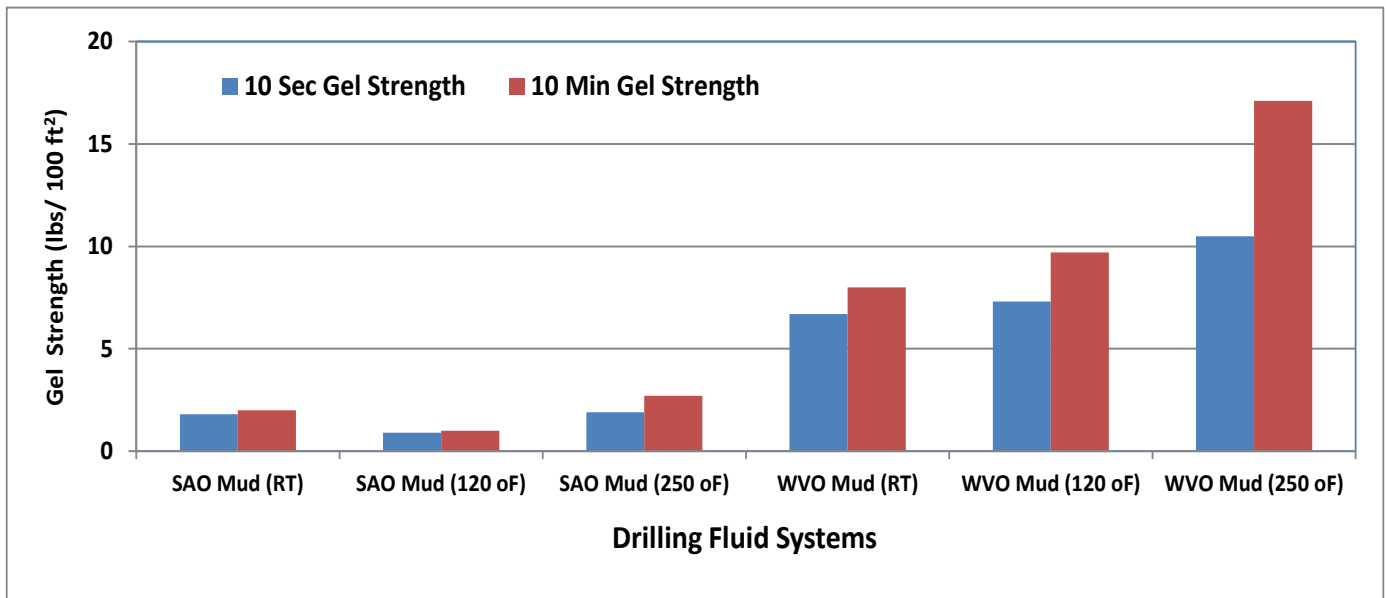

Fig. 9 Comparison of the 10/10 gel strength values of SAO and WVO-based drilling muds.

the waste vegetable oil to develop an eco-friendly OBM to explore and exploit oil and gas resources without causing any damage to other resources. As the base fluid is highly eco-friendly, virtually non-toxic and readily biodegradable, the OBM that contains it as the continuous phase will be eco-friendly.
Fig. 9 shows the 10 seconds and 10 minutes gel strength of a Saudi Arabian Oil-based mud (SAO Mud) and the newly developed waste vegetable oil ester based mud (WVO mud). The data clearly show excellent short and long term gel building characteristics for the OBM containing refined waste vegetable oil as the base 
fluid and the continuous phase. OBM system containing Saudi Arabian Oil as the continuous phase has much lower 10 seconds and 10 minutes gel strength compared to the mud containing the waste vegetable oil-based base fluid. This again demonstrates the high potential of using the refined waste vegetable oil to develop an eco-friendly OBM to explore and exploit oil and gas resources without causing any damage to other marine and terrestrial resources.

\subsection{Eco-Friendly Emulsifier}

Waste vegetable oil generated by the food and catering industry was also used to develop a primary emulsifier using a patented process. Oil from different sources including restaurants has been collected to use as the raw material for the emulsifier development. The collected waste oil blend has been filtered to remove any unwanted materials such as solid food debris and then titrated with a base to measure the acid number. It provided the information on the amount of base to be used in the synthesis process. Chemical reaction was carried out to convert the waste vegetable oil to an emulsifier. The emulsifier has then been isolated from the reaction mixture using series of steps to produce the eco-friendly emulsifier.

After the development of the eco-friendly emulsifier, an invert-emulsion mud formulation has been made using the newly developed emulsifier and a conventional base fluid which is the Safra oil in this case. Another OBM formulation was also made using the same base fluid and a commercial primary emulsifier. Both the OBM systems have same additives other than the emulsifier. However, all additives have same concentration in these two OBM systems (see Table 1). The commercial emulsifier that is currently used in OBM formulations was used to compare the performance of the newly developed ecofriendly emulsifier with respect to its performance. Compared to commercial emulsifier the newly developed emulsifier is less viscous and there is no need for dilution using solvents as in the case of commercial emulsifiers. Twelve (12) ppb of primary emulsifier loading was used for initial screening. This is followed by concentration screening of the developed emulsifier and formulations are given in Table 2.

Regular mud checks including rheological property measurement, API and HPHT filtration control properties have been carried out to compare the properties of these two mud systems. These tests were carried out after hot rolling the both mud systems at $300{ }^{\circ} \mathrm{F}$ and 500 psi for 16 hours. The experimental results are discussed below.

Fig. 10 shows the HTHP spurt and fluid loss behavior of the OBM systems in the presence of the commercial emulsifier and the newly developed eco-friendly emulsifier "ARC-Eco-Mul" that has been developed to act as a primary emulsifier (see Table 1). Both formulations showed very good and similar rheological properties.

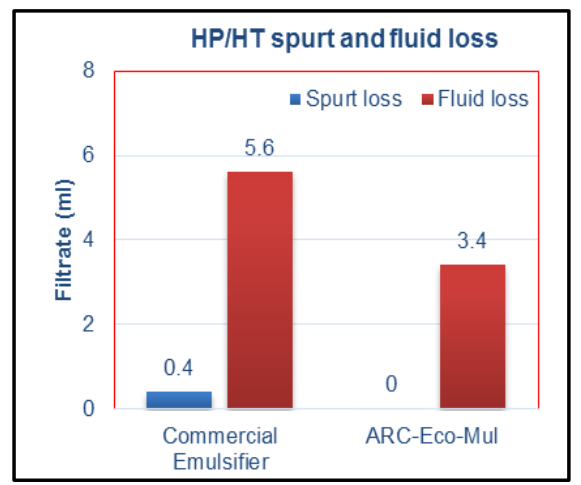

Fig. 10 HP/HT spurt and fluid loss of Commercial Emulsifier and ARC-Eco-Mul formulation.

Table 1 Comparison of emulsifier performance.

\begin{tabular}{lll}
\hline Mud system & $\begin{array}{l}\text { Formulation using } \\
\text { commercial } \\
\text { emulsifier }\end{array}$ & $\begin{array}{l}\text { Formulation using } \\
\text { ARC-Eco-Mul }\end{array}$ \\
\hline $\begin{array}{l}\text { Safra oil }(\mathrm{mL}) \\
\text { Commercial }\end{array}$ & 218 & 218 \\
Emulsifier $(\mathrm{mL})$ & 12 & 0 \\
ARC-Eco-Mul $(\mathrm{mL})$ & 0 & 12 \\
EZ-mul $(\mathrm{mL})$ & 4 & 4 \\
Lime $(\mathrm{g})$ & 6 & 6 \\
Geltone $(\mathrm{g})$ & 4 & 4 \\
Duratone $(\mathrm{g})$ & 6 & 6 \\
Brine $(61 \mathrm{~g} \mathrm{CaCl} 2$ in & 85 & 85 \\
85 cc water $)\left(\mathrm{mL}^{2}\right)$ & 161 & 161 \\
Barite $(\mathrm{g})$ & &
\end{tabular}


Table 2 Concentration screening of Arc-Eco-Mul.

\begin{tabular}{lllll}
\hline Mud system & & & & \\
\hline O/W ratio & $70 / 30$ & $70 / 30$ & $70 / 30$ & $70 / 30$ \\
\hline Safra oil (cc) & 218 & 218 & 218 & 218 \\
ARC-Eco-Mul & 12 & 6 & 4 & 0 \\
EZ-mul (cc) & 4 & 4 & 4 & 4 \\
Lime (g) & 6 & 6 & 6 & 6 \\
Geltone (g) & 4 & 4 & 4 & 4 \\
Duratone $(\mathrm{g})$ & 6 & 6 & 6 & 6 \\
Brine & 85 & 85 & 85 & 85 \\
(61 g CaCl ${ }_{2}$ in 85 cc water) & 161 & 161 & 161 & 161 \\
Barite $(\mathrm{g})$ & & &
\end{tabular}

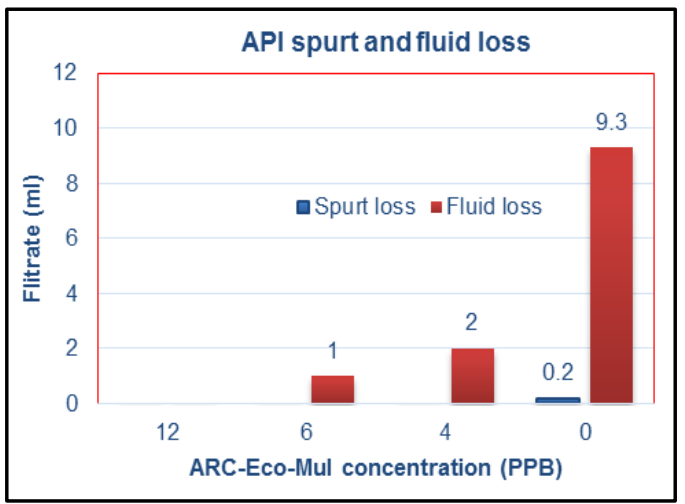

Fig. 11 API spurt and fluid loss.

The HTHP filtration control data shown in Fig. 10 clearly show better performance than the commercial emulsifier. The new emulsifier created a tighter and highly effective emulsion that allowed the better control of the fluid loss behavior of the eco-friendly emulsifier containing mud. Mud formulation containing the commercial emulsifier showed somewhat lower performance compared to the OBM containing the new emulsifier. More importantly the filtrates obtained from the HPHT filtration control experiments showed no presence of aqueous phase and thus indicates the creation of a stable emulsion by the primary emulsifiers even at HP/HT conditions.

Fig. 11 shows the API spurt and fluid loss behavior of a safra oil-based mud at various concentration of the eco-friendly emulsifier. The data indicate an optimum concentration above $6 \mathrm{ppb}$ (see Fig. 11). Hence, a concentration above $6 \mathrm{ppb}$ should be used to achieve nearly zero API fluid loss and virtually no spurt loss. It is recommended to use 6-12 ppb concentration for various application scenarios.

The possible optimum concentration range was also evaluated at HTHP conditions by measuring the HTHP spurt and fluid loss at $300{ }^{\circ} \mathrm{F}$. Fig. 12 shows the spurt and filtrate loss values measured at HTHP conditions. These data again show an optimum concentration range from 6-12 ppb to control HTHP fluid loss value below $7 \mathrm{cc}$. Hence, it is recommended to use 6-12 ppb concentration for various application scenarios.

Fig. 13 shows the photographic views of HTHP filtration data of a safra oil-based mud at 0,4 and $6 \mathrm{ppb}$ emulsifier concentration. Observation of the filtrate characteristics collected for mud having no ecofriendly emulsifier clearly demonstrates the filtration of some water during the test and also significant amount of spurt loss at the initiation of the test. This is due to the creation of a weak emulsion in the absence of the eco-friendly emulsifier. The mud containing $4 \mathrm{ppb}$ ecofriendly emulsifier also shows traces of water separation which is reflected by the lighter color at the bottom. This mud also showed spurt loss at the initiation of the test. The final formulation containing 6 ppb eco-emulsifier showed no phase separation due to the prevention of any water loss and also showed no spurt loss. This is due to the formation of a tight and effective emulsion in the presence of $6 \mathrm{ppb}$ eco-emulsifier. These data clearly indicate that a concentration range of 6 to 12 of the new emulsifier is sufficient enough to create technically effective and environmentally friendly OBM system.

Fig. 14 shows ES value of the commercial emulsifier and the newly developed eco-friendly emulsifier containing OBM systems. The data clearly show good ES values for both the mud systems. The reduction of ES value of the eco-friendly emulsifier containing OBM system after hot rolling has no negative impact on the emulsion stability of the mud system. That is why the OBM showed no phase separation after hot rolling. No separation of the HTHP filtrate at concentration above 6 already confirmed the formation of a tight and efficient emulsion. Hence, the newly 

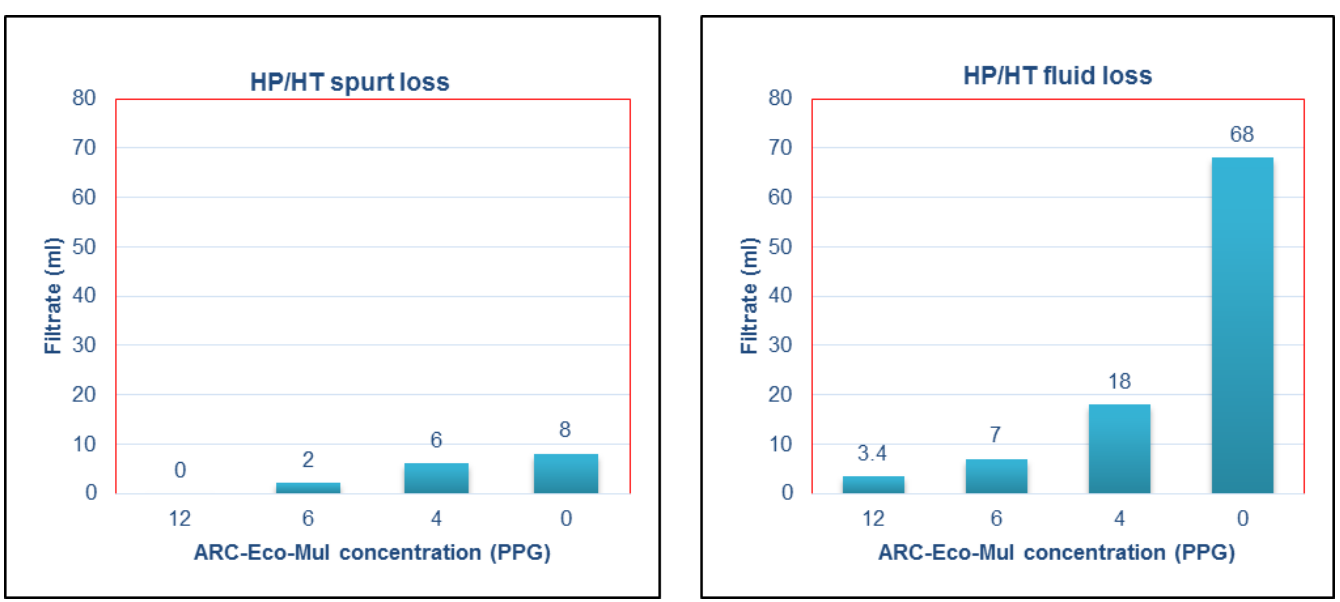

Fig. 12 HP/HT spurt and fluid loss.

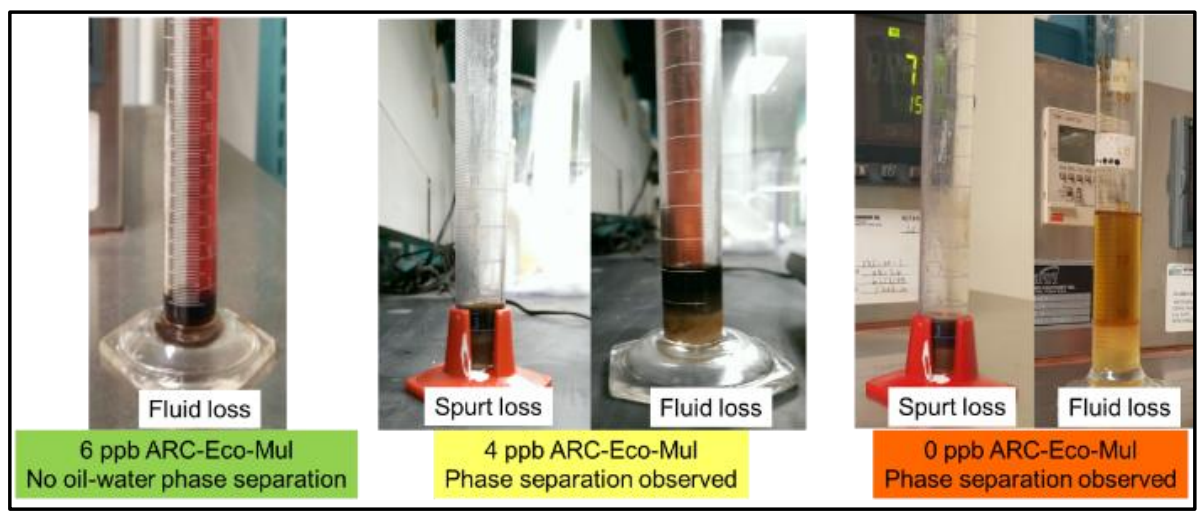

Fig. 13 Filtrate obtained from HP/HT fluid loss experiments.

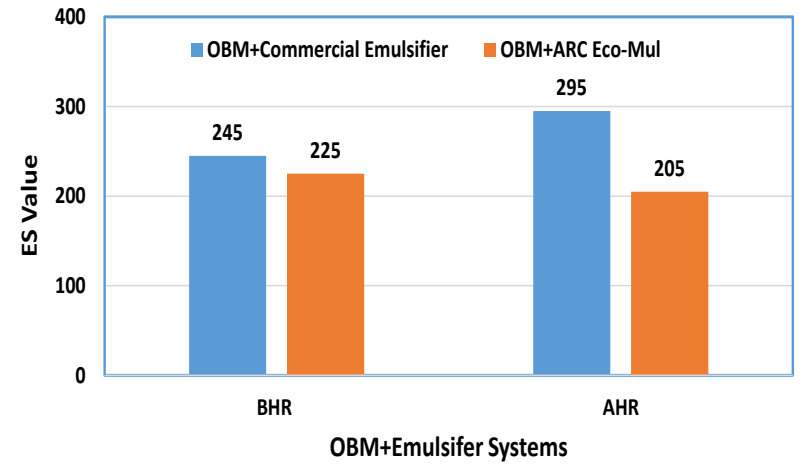

Fig. 14 ES Value of an Oil-based Mud in the Presence of Invermul and AR Eco-mul Emulsifier.

developed Eco-emulsifier will have no emulsion instability related problem.

\section{Eco-Friendly Additives for Spotting Fluid}

The waste vegetable oil-based ester was also used to formulate an eco-friendly spotting fluid coined ARC Eco-Spot by replacing the non-ecofriendly base fluid used in the traditional formulations. An in-house developed patent pending method was used to compare the performance of the eco-friendly spotting fluid with respect to two non-aqueous (Spotting Fluid A and Spotting Fluid B) and one aqueous spotting fluid (Spotting Fluid C) used by the industry. The test evaluated the degradation and reduction potential of the sticking bond modulus (SBM) and the ultimate sticking bond strength (USBS) of the base mudcake as shown in Figs. 15 and 16. The SBM was determined from the slope of the initial linear part of the load displacement curve generated during the test and the USBS was determined from the peak value of the curves.

Fig. 15 shows SBM values along with the \% reduction of the SBM values with respect to SBM value of the original mudcake which is equal to $38.24 \mathrm{kgf} / \mathrm{mm}$ (see Fig. 15) for spotting fluids A, B and C and the newly 


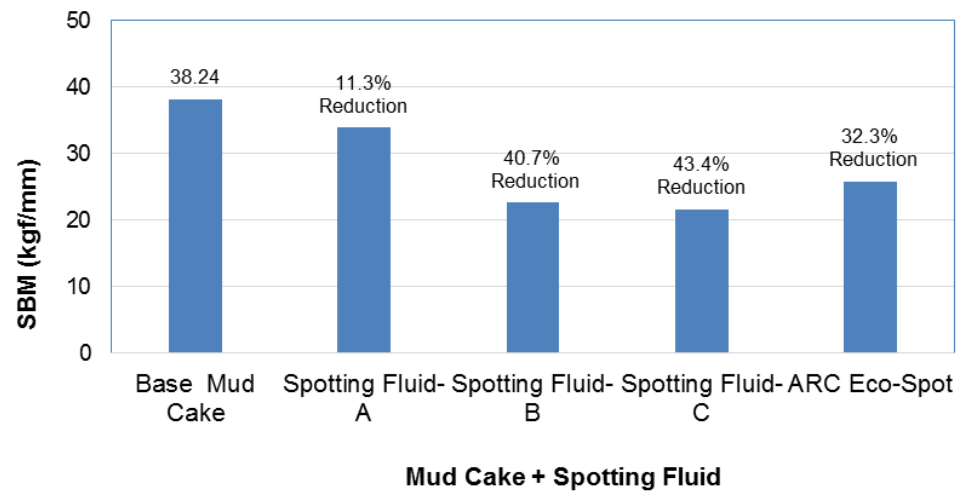

Fig. 15 SBM value alteration of base mudcake after 6 hours soaking in spotting fluids.

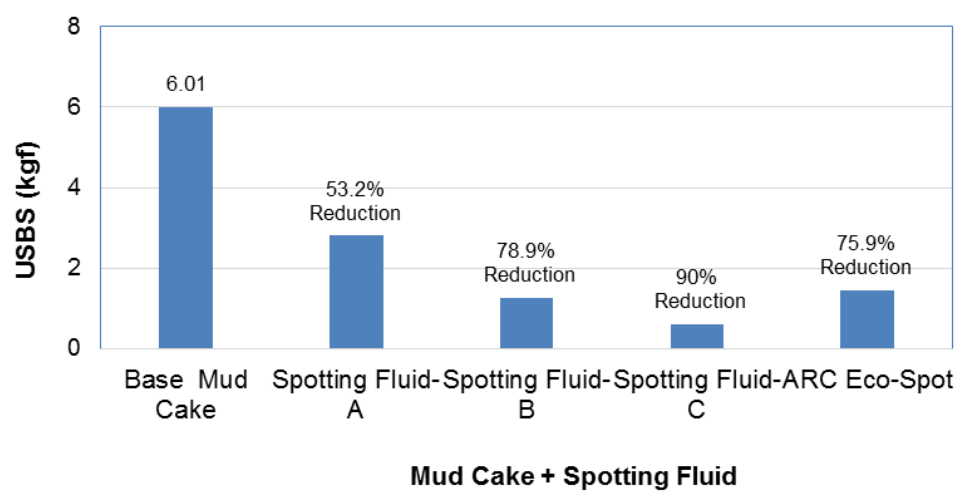

Fig, 16 USBS value alteration of base mudcake after 6 hours soaking in spotting fluids.

developed eco-friendly spotting fluid ARC Eco-Spot. The results clearly show that some of the spotting fluids have good ability to damage and degrade the sticking bonds created between a spherical metal ball and the mudcake after 6 hours soaking time in the presence of these spotting fluids. The non-aqueous spotting fluid A has the least capability to degrade the sticking bonds created between the mudcake and the metal surface of the spherical ball. The aqueous spotting fluid $\mathrm{C}$ showed the maximum reduction of the sticking bond modulus. Non-aqueous spotting fluid B has the 2nd best capability to reduce the SBM. The newly developed eco-friendly ARC Eco-Spot has the 3rd best capability in reducing the SBM values. These data clearly demonstrate the technical potential of the newly formulated eco-friendly spotting fluid to recover stuck pipe without causing any detrimental impact to the surrounding environments, eco-systems and habitats.

Fig. 16 shows \% reduction of the USBS of the original base mudcake which is equal to $6.01 \mathrm{kgf}$ (see
Fig. 16) in the presence of spotting fluids $A, B$ and $C$ and the newly developed eco-friendly spotting fluid ARC Eco-Spot. The results clearly show the variation in their performance in reducing the USBS. The non-aqueous spotting fluid $\mathrm{A}$ has the least capability to degrade the sticking bonds created between the mudcake and the metal surface of the spherical ball. Hence, it has caused minimum reduction in the USBS value. The aqueous spotting fluid $\mathrm{C}$, as before indicates the maximum reduction of the USBS. Non-aqueous spotting fluid B has the 2nd best capability to reduce the USBS. The newly developed eco-friendly spotting fluid ARC Eco-Spot has the 3rd best capability in reducing the USBS. The SBM and the USBS show the same reduction trend of their values. These data again demonstrate the technical potential of the newly formulated eco-friendly spotting fluid in recovering stuck pipes without causing any detrimental impact to the surrounding environments, eco-systems and habitats. 


\section{Conclusions}

(1) The industry is progressively shifting towards the use of ecofriendly, readily biodegradable and virtually non-toxic additives and chemicals to safeguard the global environment from any short and long term detrimental impact.

(2) The enactment of increasingly strict environmental laws and regulations by the environmental protection agencies highlights the need to replace the non-green mud additives by green mud additives for current and future drilling operation.

(3) Suitable organic by-products and/or waste products can conveniently be used to develop green mud additives both for water and oil-based drilling muds to be in the forefront of best drilling practices.

(4) Waste vegetable oil generated by the food and catering industry can be a valuable raw material for ecofriendly emulsifiers, spotting fluids and OBM development to protect the global environment.

(5) The renewable source of waste vegetable oil provides a sustainable source of huge supply of raw materials in the Kingdom for eco-friendly product development both for aqueous and non-aqueous fluid systems.

(6) The recycling and reusing of the locally available waste vegetable oil in collaboration with local industry partners will accelerate the growth and development of local industries and enterprises.

(7) The collection, delivery, processing and synthesis of waste vegetable oils can provide various green additives to substitute non- or less eco-friendly additives currently used by the industry.

(8) The plant based organic viscosifier will be able to make simultaneous contribution in controlling the fluid loss behavior and enhancing the viscous characteristics of water-based muds.

(9) The preliminary test results of OBM system containing eco-friendly base fluid as the continuous phase demonstrate its suitability for Eco-OBMs development for current and future drilling operations.

(10) The newly developed eco-friendly emulsifier showed better performance than the traditional primary emulsifier used by the industry.

(11) The waste vegetable oil ester containing eco-friendly spotting fluid will allow the recovery of a stuck pipe without causing any damage or degradation of the surrounding environments.

\section{Acknowledgements}

The authors acknowledge the support of EXPEC Advanced Research Center management for granting permission to publish this paper.

\section{References}

[1] Amanullah, Md., Bubshait, A., Allen, T. J., and Foreman, D. 2011. "The Aramco Method-Its Drilling and Production Engineering Significance." SPE/DGS Technical Symposium and Exhibition, Saudi Arabian Section, May 15-18, Khobar, Saudi Arabia. SPE-149103-MS.

[2] Tehrani, A., Gerrard, D., Young, S., and Fernandez, J. 2009. "Environmentally Friendly Water-Based Fluid for HPHT Drilling." SPE international symposium on oil field chemistry. 20-22 April, Woodlands, Texas, USA, SPE-121783-MS

[3] Rae, P., and Lullo, G. D. 2001. "Towards Environmentally-Friendly Additives for Well Completion and Stimulation Operations." SPE Asia Pacific Oil and Gas Conf. \& Exhib. 17-19 April, Jakarta, Indonesia, SPE- 68651-MS.

[4] Alkhowaildi, M. A., AlGhazal, M. A., Al-Driweesh, S., Abbad, E., and Abdrabalnabi, H. 2016. "Eco-Friendly Hydraulic Fracturing Fluid: Field Deployment and Performance Evaluation in Saudi Arabia's Tight Gas Reservoirs." SPE Asia Pacific Hydraulic Fracturing Conference, Beijing, China 24-26 August, SPE-181861-MS

[5] Peresich, R. L., Burrell, B. R., and Prentice, G. M. 1991. "Development and Field Trial of a Biodegradable Invert Emulsion Fluid." SPE/IADC Drilling Conference, Amsterdam, the Netherlands, March 11-14. SPE-21935-MS.

[6] Bland, R. G., Clapper, D. K., Fleming, N. M., and Hood, C. A. 1993. "Biodegradation and Drilling Fluid Chemicals." SPE/IADC Drilling Conference, Amsterdam, the Netherlands, February 22-25, SPE-25754-MS.

[7] Amanullah, M., Ramasamy, J., and Al-Arfaj, M. K. 2016. "Application of an Indigenous Eco-Friendly Raw Material as Fluid Loss Additive." J. Petroleum Science and Engineering 139: 191-7. 
[8] Ramasamy, J., and Amanullah, M. 2017. "Novel Fibrous Lost Circulation Materials Derived from Deceased Date Tree Waste." SPE Kingdom of Saudi Arabia Annual Technical Symposium and Exhibition, 24-27 April, Dammam, Saudi Arabia, SPE-187989-MS.

[9] Ramasamy, J., Amanullah, M., and Alsaihati, M. M. 2018. "Emulsifier Developed from Waste Vegetable Oil for Application in Invert-Emulsion Oil Based Mud." SPE Kingdom of Saudi Arabia Annual Technical Symposium and Exhibition, 23-26 April, Dammam, Saudi Arabia, SPE-192230-MS.

[10] Ramasamy, J., and Amanullah, M. 2018. "A Novel Superfine Fibrous Lost Circulation Material Derived From Date Tree for Seepage Loss Control." SPE Kingdom of Saudi Arabia Annual Technical Symposium and Exhibition, 23-26 April, Dammam, Saudi Arabia, SPE-192229-MS.

[11] Ramasamy, J., and Amanullah, M. 2019. "Converting Waste Vegetable Oil to Emulsifier for Invert-Emulsion Oil Based Mud." International Petroleum Technology Conference, 26-28 March, Beijing, China, IPTC-19493-MS.

[12] Amanullah, M., and Al-Arfaj, M. K. 2018. "Waste Cooking Oil-A Potential Source of Raw Material for Localization of Green Products Development." SPE Kingdom of Saudi Arabia Annual Technical Symposium and Exhibition, 23-26 April, Dammam, Saudi Arabia, SPE-192162-MS.

[13] Amanullah, M., and Al-Arfaj, M. K. 2018. "Date Palm Tree-Based Fibrous LCM 'ARC Eco-Fiber'-A Better Alternative to Equivalent Imported Products." SPE Kingdom of Saudi Arabia Annual Technical Symposium and Exhibition, 23-26 April, Dammam, Saudi Arabia, SPE-192160-MS.

[14] Amanullah, M., Al-Arfaj, M. K., and Alouhali, R. 2019. "Novel Plant-Based Particulate and Fibrous LCM Products for Loss Control while Drilling." International Petroleum Technology Conference, 26-28 March, Beijing, China, IPTC-19305-MS.

[15] Amanullah, M., and Al-Arfaj, M. K. 2017. "Novel Method and Apparatus for Sticking Fluid Performance
Evaluation." SPE Kingdom of Saudi Arabia Annual Technical Symposium and Exhibition, Dammam, Saudi Arabia, April 24-27, SPE-187982-MS.

[16] Srivastava, A., and Prasad, R. 2000. "Triglycerides-based Diesel Fuels." Renewable and Sustainable Energy Reviews 4 (2): 111-33.

[17] Sidibé, S. S., Blin, J., Vaitilingom, G., and Azoumah, Y. 2010. "Use of Crude Filtered Vegetable Oil as a Fuel in Diesel Engines State-of-the-Art: Literature Review." Renewable and Sustainable Energy Reviews 14 (9): 2748-59.

[18] Daan, R., and Mulder, M. 1994. "Long-Term Effects of OBM Cutting Discharges in the Sandy Erosion Area of the Dutch Continental Shelf." Netherlands Institute for Sea Research Report 28 (4): 26.

[19] Friedheim, J. E., and Conn, H. L. 1996. "Second Generation Synthetic Fluids in the North Sea: Are They Better?" SPE/IADC Drilling Conference, New Orleans, Louisiana, March 12-15, SPE-35061-MS.

[20] Candler, J., Churan, M., and Conn, L. 1996. "Laboratory and Field Measurement of Vapors Generated by Organic Materials in Drilling Fluid." International Conference on Health, Safety and Environment in oil and Gas Exploration and Production. New Orleans, Louisiana, USA, SPE-35866-MS.

[21] Cordah. 1998. "Review of Drill Cuttings Piles in the North Sea. Report for Offshore Decommissioning Communication Project." Cordah Environmental Consultants, Aberdeen, Scotland.

[22] Daan, R. K., Booij, M., and Van Weerlee, E. M. 1996. "Environmental Effects of Discharge of Drill Cuttings Contaminated with Ester-based Drilling Muds in the North Sea." Environmental Toxicological Chemistry 15: 1709-22.

[23] Neff, J. M., McKelvie, S., and Ayers, R. C. Jr. 2000. "Environmental Impacts of Synthetic Based Drilling Fluids." Report prepared for MMS by Robert Ayers \& Associates, Inc. August 2000. U.S. Department of the Interior, Minerals Management Service, Gulf of Mexico OCS Region, New Orleans, LA. OCS Study MMS 2000-064, p. 118. 